\title{
STRONG CONVERGENCE THEOREMS FOR FIXED POINTS OF PSEUDO-CONTRACTIVE SEMIGROUP
}

\author{
Xue-song Li and Nan-Jing Huang
}

\begin{abstract}
We study some convergence of two kinds of implicit iteration processes for approximating common fixed points of a pseudo-contractive semigroup in uniformly convex Banach spaces with uniformly Gâteaux differential norms. As special cases, we get some convergence of the implicit iteration processes for approximating common fixed points of a nonexpansive semigroup in uniformly smooth Banach spaces and give a positive answer to an open problem proposed by $\mathrm{Xu}$ in Bull. Austral. Math. Soc. (2005). The results presented in this paper generalise some corresponding results from Osilike in Panamer. Math. J. (2004), Suzuki in Proc. Amer. Math. Soc. (2002) and $\mathrm{Xu}$ in Bull. Austral. Math. Soc. (2005).
\end{abstract}

\section{INTRODUCTION}

Let $E$ be a real Banach space with the dual space $E^{*}$ and $J: E \rightarrow 2^{E^{*}}$ be a normalised duality mapping defined by

$$
J(x)=\left\{x^{*} \in E^{*}:\left\langle x, x^{*}\right\rangle=\|x\|^{2}=\left\|x^{*}\right\|^{2}\right\},
$$

where $\langle\cdot, \cdot\rangle$ denotes the generalised duality pairing. It is well known that (see, for example, [10, pp. 107-113])

(i) $J$ is single-valued if $E^{*}$ is strictly convex;

(ii) $E$ is uniformly smooth if and only if $J$ is single-valued and uniformly continuous on any bounded subset of $E$.

Let $K$ be a nonempty closed convex subset of $E$. A mapping $T: K \rightarrow K$ is said to be

(i) nonexpansive if

$$
\|T x-T y\| \leqslant\|x-y\|, \quad \forall x, y \in K
$$

Received 16th April, 2007

This work was supported by the National Natural Science Foundation of China (10671135) and the Specialised Research Fund for the Doctoral Program of Higher Education (20060610005).

Copyright Clearance Centre, Inc. Serial-fee code: 0004-9727/07 \$A2.00+0.00. 
(ii) $L$-Lipschitzian if there exists a constant $L>0$ such that

$$
\|T x-T y\| \leqslant L\|x-y\|, \quad \forall x, y \in K
$$

(iii) strongly pseudo-contractive if there exist a constant $\alpha \in(0,1)$ and $j(x-y) \in J(x-y)$ such that

$$
\langle T x-T y, j(x-y)\rangle \leqslant \alpha\|x-y\|^{2}, \quad \forall x, y \in K
$$

(iv) pseudo-contractive if there exists $j(x-y) \in J(x-y)$ such that

$$
\langle T x-T y, j(x-y)\rangle \leqslant\|x-y\|^{2}, \quad \forall x, y \in K
$$

Obviously, the mapping $T$ is pseudo-contractive if and only if the mapping $A=I-T$ is accretive on $K$, where $I$ is an identity mapping (see [2, 4]); pseudocontractive mappings are more general than nonexpansive mappings.

A pseudo-contractive semigroup is a family

$$
\Gamma:=\{T(t): t \geqslant 0\}
$$

of self-mappings on $\mathrm{K}$ such that

(1) $T(0) x=x$ for all $x \in K$;

(2) $T(s+t) x=T(s) T(t) x$ for all $x \in K$ and $s, t \geqslant 0$;

(3) $T(t)$ is pseudo-contractive for each $t \geqslant 0$;

(4) for each $x \in K$, the mapping $T(\cdot) x$ from $R^{+}$into $K$ is continuous.

If the mapping $T(t)$ in condition (3) is replaced by

$(3)^{\prime} T(t)$ is nonexpansive for each $t \geqslant 0 ;$

then $\Gamma:=\{T(t): t \geqslant 0\}$ is said to be a nonexpansive semigroup on $K$.

We denote by $F(\Gamma)$ the common fixed point set of a pseudo-contractive semigroup $\Gamma$; that is,

$$
F(\Gamma)=\cap_{t \in R^{+}} F(T(t))=\{x \in K: T(t) x=x \text { for each } t \geqslant 0\}
$$

In the sequel, we always assume $F(\Gamma) \neq \emptyset$.

Let $T$ be a nonexpansive mapping from $K$ into itself. For any given $u \in K$ and each $t \in(0,1)$, it follows from Banach's fixed theorem that the following implicit iteration process is well defined:

$$
x_{t}=t u+(1-t) T x_{t}
$$

Browder [1] (Reich [8], respectively) proved that as $t \rightarrow 0, x_{t}$ converges strongly to some fixed point of $T$ in Hilbert space (uniformly smooth Banach space, respectively). 
An interesting work is to extend Browder's and Reich's results to semigroups. Recently, Suzuki [9] firstly introduced and studied the following implicit iteration sequence constructed from a nonexpansive semigroup in Hilbert space, for any given $u \in K$,

$$
x_{n}=\alpha_{n} u+\left(1-\alpha_{n}\right) T\left(t_{n}\right) x_{n}, \quad \forall n \geqslant 1,
$$

where $\alpha_{n} \in(0,1)$, and obtained the convergence theorem under certain appropriate assumptions imposed on the parameters $\left\{\alpha_{n}\right\}$ and $\left\{t_{n}\right\}$. Very recently, Xu [12] studied the convergence of (1.2) in a uniformly convex Banach space with a weakly continuous duality mapping and obtained some convergence theorems for nonexpansive semigroup as follows:

THEOREM X. ([12]) Let $E$ be a uniformly convex Banach space having a weakly continuous duality map $J_{\varphi}$ with gauge $\varphi, K$ a nonempty closed convex subset of $E$ and

$$
\Gamma:=\{T(t): t \geqslant 0\}
$$

a nonexpansive semigroup on $K$ such that $\operatorname{Fix}(\Gamma) \neq \emptyset$. If

$$
\lim _{n \rightarrow \infty} t_{n}=\lim _{n \rightarrow \infty} \frac{\alpha_{n}}{t_{n}}=0
$$

then $\left\{x_{n}\right\}$ generated by (1.2) converges strongly to a member of $F$.

$\mathrm{Xu}$ [12] also proposed the following problem:

Problem X. ([12]) We do not know if Theorem $X$ holds in a uniformly convex and uniformly smooth Banach space (for example, $L^{p}$ for $1<p<\infty$ ).

On the other hand, $\mathrm{Xu}$ and Ori [13] introduced the following implicit iteration process constructed from a finite family of nonexpansive mappings in Hilbert space, for any given $x_{0} \in K$,

$$
x_{n}=\alpha_{n} x_{n-1}+\left(1-\alpha_{n}\right) T_{n} x_{n}, \quad \forall n \geqslant 1,
$$

where $T_{n}=T_{n(\bmod N)}$ and $\alpha_{n} \in(0,1)$. Furthermore, Osilike [6] extended the results of $\mathrm{Xu}$ and Ori [13] from the class of nonexpansive mappings to the more general class of Lipschitzian pseudo-contractive mappings.

It is also an interesting work to extend Osilike's results to semigroup. Thus, we introduce the following implicit iteration process constructed from a pseudo-contractive semigroup $\Gamma:=\{T(t): t \geqslant 0\}$ in a real Banach space, for any given $x_{0} \in K$,

$$
x_{n}=\alpha_{n} x_{n-1}+\left(1-\alpha_{n}\right) T\left(t_{n}\right) x_{n}, \quad \forall n \geqslant 1,
$$

where $T\left(t_{n}\right) \in \Gamma$ and $\alpha_{n} \in(0,1)$.

In this paper, we study the convergence of the implicit iteration process (1.2) constructed from the pseudo-contractive semigroup $\Gamma:=\left\{T(t): t \in R^{+}\right\}$in uniformly convex 
Banach spaces with uniformly Gâteaux differential norms. As a special case, we obtain the convergence of the implicit iteration process for approximating the common fixed point of the nonexpansive semigroup in uniformly smooth Banach spaces, which gives a positive answer to Problem X proposed by Xu [12]. We also study the convergence of the implicit iteration process (1.4) constructed from the pseudo-contractive semigroup $\Gamma$ in uniformly convex Banach spaces with uniformly Gâteaux differential norms. The results presented in this paper generalise some corresponding results in $[6,9,12]$.

\section{Preliminaries}

A real Banach space $E$ is said to have a weakly continuous duality mapping if $J$ is single-valued and weak-to-weak ${ }^{*}$ sequentially continuous (that is, if each $\left\{x_{n}\right\}$ is a sequence in $E$ weakly convergent to $x$, then $\left\{J\left(x_{n}\right)\right\}$ converges weakly* to $J(x)$ ). Obviously, if $E$ has a weakly continuous duality mapping, then $J$ is norm-to-weak ${ }^{*}$ sequentially continuous. It is well known that $l^{p}(1<p<\infty)$ posesses duality mapping which is weakly continuous (see, for example, [12]).

Let $l^{\infty}$ be the Banach space of all bounded real-valued sequences. A Banach limit LIM (see [10]) is a linear continuous functional on $l^{\infty}$ such that

$$
\|\operatorname{LIM}\|=\operatorname{LIM}(1)=1, \quad \operatorname{LIM}\left(t_{1}, t_{2}, \ldots\right)=\operatorname{LIM}\left(t_{2}, t_{3}, \ldots\right)
$$

for each $t=\left(t_{1}, t_{2}, \ldots\right) \in l^{\infty}$. If LIM is a Banach limit, then it follows from [10, Theorem 1.4.4] that

$$
\liminf _{n \rightarrow \infty} t_{n} \leqslant \operatorname{LIM}(t) \leqslant \limsup _{n \rightarrow \infty} t_{n}
$$

for each $t=\left(t_{1}, t_{2}, \ldots\right) \in l^{\infty}$.

A Banach space $E$ is said to satisfy Opial's condition if whenever $\left\{x_{n}\right\}$ is a sequence in $E$ which converges weakly to $x$, then

$$
\limsup _{n \rightarrow \infty}\left\|x_{n}-x\right\|<\limsup _{n \rightarrow \infty}\left\|x_{n}-y\right\|
$$

for all $y \in E$ with $y \neq x$. It is well known that every Hilbert space satisfies the Opial's condition (see, for example, [5]).

A mapping $T$ with domain $D(T)$ and range $R(T)$ in $E$ is said to be demiclosed at a point $p \in E$ if whenever $\left\{x_{n}\right\}$ is a sequence in $D(T)$ which converges weakly to $x \in D(T)$ and $\left\{T x_{n}\right\}$ converges strongly to $p$, then $T x=p$.

For the sake of convenience, we restate the following lemmas that shall be used.

Lemma 2.1. ([3]) Let $E$ be a Banach space, $K$ be a nonempty closed convex subset of $E$ and $T: K \rightarrow K$ be a strongly pseudo-contractive and continuous mapping. Then $T$ has a unique fixed point in $K$. 
LEMMA 2.2. ([7]) Let $E$ be a Banach space and $J$ be the normalised duality mapping. Then for any $x, y \in E$ and $j(x+y) \in J(x+y)$,

$$
\|x+y\|^{2} \leqslant\|x\|^{2}+2\langle y, j(x+y)\rangle .
$$

Lemma 2.3. ([13]) Let $r>0$. Then a real Banach space $E$ is uniformly convex if and only if there exists a continuous and strictly increasing convex function $g:[0, \infty)$ $\rightarrow[0, \infty)$ with $g(0)=0$ such that

$$
\|\lambda x+(1-\lambda) y\|^{2} \leqslant \lambda\|x\|^{2}+(1-\lambda)\|y\|^{2}-\lambda(1-\lambda) g(\|x-y\|)
$$

for all $x, y \in B_{r}, \lambda \in[0,1]$, where $B_{r}=\{x \in E:\|x\| \leqslant r\}$.

\section{Main Results}

We first discuss the convergence of implicit iteration process (1.2) constructed from a pseudo-contractive semigroup $\Gamma:=\{T(t): t \geqslant 0\}$.

THEOREM 3.1. Let $K$ be a nonempty closed convex subset of a real Banach space $E$ and $\Gamma:=\left\{T(t): t \in R^{+}\right\}$be a strongly continuous L-Lipschitzian semigroup of pseudo-contractive mappings. Then the sequence $\left\{x_{n}\right\}$ generated by (1.2) is well defined. Moreover, if

$$
\lim _{n \rightarrow \infty} t_{n}=\lim _{n \rightarrow \infty} \frac{\alpha_{n}}{t_{n}}=0,
$$

then $\lim _{n \rightarrow \infty}\left\|x_{n}-T(t) x_{n}\right\|=0$ for any $t \in R^{+}$.

ProOF: Let

$$
T_{n} x:=\alpha_{n} u+\left(1-\alpha_{n}\right) T\left(t_{n}\right) x, \quad \forall n \geqslant 1
$$

Since

$$
\begin{aligned}
\left\langle T_{n} x-T_{n} y, j(x-y)\right\rangle & =\left(1-\alpha_{n}\right)\left\langle T\left(t_{n}\right) x-T\left(t_{n}\right) y, j(x-y)\right\rangle \\
& \leqslant\left(1-\alpha_{n}\right)\|x-y\|^{2},
\end{aligned}
$$

we know that $T_{n}$ is strongly pseudo-contractive and strongly continuous. It follows from Lemma 2.1 that $T_{n}$ has a unique fixed point (say) $x_{n} \in K$, that is, $\left\{x_{n}\right\}$ generated by (1.2) is well defined.

Taking $p \in F(\Gamma)$, we have

$$
\begin{aligned}
\left\|x_{n}-p\right\|^{2} & =\alpha_{n}\left\langle u-p, j\left(x_{n}-p\right)\right\rangle+\left(1-\alpha_{n}\right)\left\langle T\left(t_{n}\right) x_{n}-T\left(t_{n}\right) p, j\left(x_{n}-p\right)\right\rangle \\
& \leqslant \alpha_{n}\|u-p\|\left\|j\left(x_{n}-p\right)\right\|+\left(1-\alpha_{n}\right)\left\|x_{n}-p\right\|^{2} \\
& =\alpha_{n}\|u-p\|\left\|x_{n}-p\right\|+\left(1-\alpha_{n}\right)\left\|x_{n}-p\right\|^{2}
\end{aligned}
$$


and so $\left\|x_{n}-p\right\| \leqslant\|u-p\|$. This means $\left\{x_{n}\right\}$ is bounded. By the Lipschitzian condition of $\Gamma$, it follows that $\left\{T\left(t_{n}\right) x_{n}\right\}$ is bounded. Therefore,

$$
\left\|x_{n}-T\left(t_{n}\right) x_{n}\right\|=\alpha_{n}\left\|u-T\left(t_{n}\right) x_{n}\right\| \rightarrow 0 .
$$

For any given $t>0$,

$$
\begin{aligned}
\left\|x_{n}-T(t) x_{n}\right\| & =\sum_{k=0}^{\left[t / t_{n}\right]-1}\left\|T\left((k+1) t_{n}\right) x_{n}-T\left(k t_{n}\right) x_{n}\right\|+\left\|T(t) x_{n}-T\left(\left[t / t_{n}\right] t_{n}\right) x_{n}\right\| \\
& \leqslant\left[t / t_{n}\right] L\left\|x_{n}-T\left(t_{n}\right) x_{n}\right\|+L\left\|T\left(t-\left[t / t_{n}\right] t_{n}\right) x_{n}-x_{n}\right\| \\
& \leqslant t L \frac{\alpha_{n}}{t_{n}}\left\|u-T\left(t_{n}\right) x_{n}\right\|+L \max \left\{\left\|T(s) x_{n}-x_{n}\right\|: 0 \leqslant s \leqslant t_{n}\right\},
\end{aligned}
$$

where $\left[t / t_{n}\right]$ is the integral part of $t / t_{n}$. Since $\lim _{n \rightarrow \infty}\left(\alpha_{n} / t_{n}\right)=0$ and $T(\cdot) x: R^{+} \rightarrow K$ is continuous for any $x \in K$, we have

$$
\lim _{n \rightarrow \infty}\left\|x_{n}-T(t) x_{n}\right\|=0
$$

This completes the proof.

THEOREM 3.2. Let $E$ be a uniformly convex Banach space with the uniformly Gâteaux differential norm and $K$ be a nonempty closed convex subset of $E$. Let $\Gamma:=\left\{T(t): t \in R^{+}\right\}$be a strongly continuous L-Lipschitzian semigroup of pseudocontractive mappings and $\left\{x_{n}\right\}$ be generated by (1.2). If the following conditions hold:

(1) $\lim _{n \rightarrow \infty}\left(\alpha_{n} / t_{n}\right)=\lim _{n \rightarrow \infty} t_{n}=0$;

(2) $\operatorname{LIM}\left\|T(t) x_{n}-T(t) x^{*}\right\| \leqslant \operatorname{LIM}\left\|x_{n}-x^{*}\right\|, \quad \forall x^{*} \in C, t \in R^{+}$, where $C:=\left\{x^{*} \in K: \Phi\left(x^{*}\right)=\min _{x \in K} \Phi(x)\right\}$ with $\Phi(x)=\operatorname{LIM}\left\|x_{n}-x\right\|^{2}$ for all $x \in K$;

then $\left\{x_{n}\right\}$ converges strongly to a member of $F(\Gamma)$.

PROOF: From Theorem 3.1, we know that $\left\{x_{n}\right\}$ is bounded and $\lim _{n \rightarrow \infty}\left\|x_{n}-T(t) x_{n}\right\|$ $=0$. It is easy to see that $C$ is a nonempty bounded closed convex subset of $K$ (see, for example [11]).

Now, we show that there exists a common fixed point of $\Gamma$ in $C$. For any $t \in R^{+}$ and $x^{*} \in C$, it follows from $\lim _{n \rightarrow \infty}\left\|x_{n}-T(t) x_{n}\right\|=0$ that

$$
\begin{aligned}
\Phi\left(T(t) x^{*}\right) & =\operatorname{LIM}\left\|x_{n}-T(t) x^{*}\right\|^{2} \\
& =\operatorname{LIM}\left\|T(t) x_{n}-T(t) x^{*}\right\|^{2} \\
& \leqslant \operatorname{LIM}\left\|x_{n}-x^{*}\right\|^{2} \\
& =\Phi\left(x^{*}\right)
\end{aligned}
$$


and so

$$
T(t)(C) \subset C .
$$

Next, we prove that $C$ is a singleton. In fact, since $E$ is uniformly convex, by Lemma 2.3 that there exists a continuous and strictly increasing convex function $g:[0, \infty) \rightarrow[0, \infty)$ with $g(0)=0$ such that, for any $x_{1}^{*}$ and $x_{2}^{*} \in C$,

$$
\left\|x_{n}-\frac{x_{1}^{*}+x_{2}^{*}}{2}\right\|^{2} \leqslant \frac{1}{2}\left\|x_{n}-x_{1}^{*}\right\|^{2}+\frac{1}{2}\left\|x_{n}-x_{2}^{*}\right\|^{2}-\frac{1}{4} g\left(\left\|x_{1}^{*}-x_{2}^{*}\right\|\right) .
$$

Taking Banach limit LIM on the above inequality, it follows that

$$
\begin{aligned}
\frac{1}{4} g\left(\left\|x_{1}^{*}-x_{2}^{*}\right\|\right) & \leqslant \frac{1}{2} \operatorname{LIM}\left\|x_{n}-x_{1}^{*}\right\|^{2}+\frac{1}{2} \operatorname{LIM}\left\|x_{n}-x_{2}^{*}\right\|^{2}-\operatorname{LIM}\left\|x_{n}-\frac{x_{1}^{*}+x_{2}^{*}}{2}\right\|^{2} \\
& \leqslant 0 .
\end{aligned}
$$

This implies $x_{1}^{*}=x_{2}^{*}$ and so $C$ is a singleton. Therefore, (3.2) implies that there exists $x^{*} \in C$ such that $x^{*} \in F(\Gamma)$.

For any $p \in F(\Gamma)$, from (1.2), we have

$$
\begin{aligned}
\left\langle x_{n}-u, j\left(x_{n}-p\right)\right\rangle & =\frac{1-\alpha_{n}}{\alpha_{n}}\left\langle T\left(t_{n}\right) x_{n}-x_{n}, j\left(x_{n}-p\right)\right\rangle \\
& =\frac{1-\alpha_{n}}{\alpha_{n}}\left[\left\langle T\left(t_{n}\right) x_{n}-T\left(t_{n}\right) p, j\left(x_{n}-p\right)\right\rangle-\left\langle x_{n}-p, j\left(x_{n}-p\right)\right\rangle\right] \\
& \leqslant 0 .
\end{aligned}
$$

Since $x^{*} \in F(\Gamma)$, it follows from (3.3) that

$$
\operatorname{LIM}\left\langle x_{n}-u, j\left(x_{n}-x^{*}\right)\right\rangle \leqslant 0 .
$$

Furthermore, for any $t \in(0,1)$, by Lemma 2.2 , we have

$$
\begin{aligned}
\left\|x_{n}-x^{*}-t\left(u-x^{*}\right)\right\|^{2} \leqslant & \left\|x_{n}-x^{*}\right\|^{2}-2 t\left\langle u-x^{*}, j\left(x_{n}-x^{*}-t\left(u-x^{*}\right)\right)\right\rangle \\
\leqslant & \left\|x_{n}-x^{*}\right\|^{2}-2 t\left\langle u-x^{*}, j\left(x_{n}-x^{*}\right)\right\rangle \\
& -2 t\left\langle u-x^{*}, j\left(x_{n}-x^{*}-t\left(u-x^{*}\right)\right)-j\left(x_{n}-x^{*}\right)\right\rangle
\end{aligned}
$$

and

$$
\begin{aligned}
\left\langle u-x^{*}, j\left(x_{n}-x^{*}\right)\right\rangle \leqslant & \frac{1}{2 t}\left[\left\|x_{n}-x^{*}\right\|^{2}-\left\|x_{n}-x^{*}-t\left(u-x^{*}\right)\right\|^{2}\right] \\
& -\left\langle u-x^{*}, j\left(x_{n}-x^{*}-t\left(u-x^{*}\right)\right)-j\left(x_{n}-x^{*}\right)\right\rangle .
\end{aligned}
$$

For any $\varepsilon>0$, since $E$ has a uniformly Gâteaux differential norm, we know that $J$ is norm-to-weak* uniformly continuous on any bounded subset of $E$ (see, for example, [10, pp.107-113]) and so there exists sufficient small $\delta(\varepsilon)>0$ such that

$$
\left\langle u-x^{*}, j\left(x_{n}-x^{*}\right)\right\rangle \leqslant \frac{1}{2 t}\left[\left\|x_{n}-x^{*}\right\|^{2}-\left\|x_{n}-x^{*}-t\left(u-x^{*}\right)\right\|^{2}\right]+\varepsilon, \quad \forall t \in(0, \delta) .
$$


This implies that

$\operatorname{LIM}\left\langle u-x^{*}, j\left(x_{n}-x^{*}\right)\right\rangle \leqslant \frac{1}{2 t}\left[\operatorname{LIM}\left\|x_{n}-x^{*}\right\|^{2}-\operatorname{LIM}\left\|x_{n}-x^{*}-t\left(u-x^{*}\right)\right\|^{2}\right]+\varepsilon<\varepsilon$.

By the arbitrariness of $\varepsilon$, it follows that

$$
\operatorname{LIM}\left\langle u-x^{*}, j\left(x_{n}-x^{*}\right)\right\rangle \leqslant 0 .
$$

Adding inequalities (3.4) and (3.5), we have

$$
\operatorname{LIM}\left\langle x_{n}-x^{*}, j\left(x_{n}-x^{*}\right)\right\rangle=\operatorname{LIM}\left\|x_{n}-x^{*}\right\|^{2} \leqslant 0 .
$$

This implies that there exists subsequence $\left\{x_{n_{j}}\right\} \subset\left\{x_{n}\right\}$ which converges strongly to $x^{*}$. From the proof of (3.6), we know that LIM $\left\|x_{n_{l}}-x^{*}\right\|^{2} \leqslant 0$ for any subsequence $\left\{x_{n_{l}}\right\} \subset\left\{x_{n}\right\}$ and so there exists subsequence of $\left\{x_{n_{l}}\right\}$ which converges strongly to $x^{*}$. If there exists another subsequence $\left\{x_{n_{k}}\right\} \subset\left\{x_{n}\right\}$ which converges strongly to $y^{*}$, then it follows from Theorem 3.1 that $y^{*} \in F(\Gamma)$. From (3.3), we have

$$
\left\langle x^{*}-u, j\left(x^{*}-y^{*}\right)\right\rangle \leqslant 0, \quad\left\langle y^{*}-u, j\left(y^{*}-x^{*}\right)\right\rangle \leqslant 0 .
$$

This implies that $\left\|x^{*}-y^{*}\right\|^{2} \leqslant 0$ and so $x^{*}=y^{*}$. Therefore, $\left\{x_{n}\right\}$ converges strongly to $x^{*} \in F(\Gamma)$. This completes the proof.

If $\Gamma:=\left\{T(t): t \in R^{+}\right\}$is a nonexpansive semigroup, then $\Gamma:=\left\{T(t): t \in R^{+}\right\}$is a strongly continuous $L$-Lipschitzian semigroup of pseudo-contractive mappings. From Theorem 3.2, we have the following result.

Corollary 3.1. Let $E$ be a uniformly convex Banach space with the uniformly Gâteaux differential norm and $K$ be a nonempty closed convex subset of $E$. Let $\Gamma:=\left\{T(t): t \in R^{+}\right\}$be a nonexpansive semigroup and $\left\{x_{n}\right\}$ be generated by (1.2). If

$$
\lim _{n \rightarrow \infty} \frac{\alpha_{n}}{t_{n}}=\lim _{n \rightarrow \infty} t_{n}=0
$$

then $\left\{x_{n}\right\}$ converges strongly to a member of $F(\Gamma)$.

REMARK 3.1. If $E$ is a uniformly smooth Banach space, then $E$ has the uniformly Gâteaux differential norm. Thus, Corollary 3.1 gives a positive answer to Problem X proposed by Xu [12].

THEOREM 3.3. Let $E$ be a uniformly smooth Banach space and $K$ be a nonempty closed convex subset of $E$. Let $\Gamma:=\left\{T(t): t \in R^{+}\right\}$be a nonexpansive semigroup and $\left\{x_{n}\right\}$ be generated by (1.2). If

$$
\lim _{n \rightarrow \infty} \frac{\alpha_{n}}{t_{n}}=\lim _{n \rightarrow \infty} t_{n}=0
$$

then $\left\{x_{n}\right\}$ converges strongly to a member of $F(\Gamma)$. 
Proof: For the nonexpansive semigroup $\Gamma$, condition (2) of Theorem 3.2 is trivial and so formula (3.2) holds. Since uniformly smooth Banach space $E$ has the fixed point property for nonexpansive mapping $T(t)$ (see, for example, [11]), $T(t)$ has a fixed point $x^{*} \in C \cap F(\Gamma)$. The rest proof is similar to the proof of Theorem 3.2 and so we omit it. This completes the proof.

Remark 3.2. Theorem 3.3 gives a positive answer to Problem $\mathrm{X}$ proposed by $\mathrm{Xu}$ [12] in a uniformly smooth Banach space $E$ without the uniform convexity.

TheOREM 3.4. Let $E$ be a real Hilbert space and $K$ be a nonempty closed convex subset of $E$. Let $\Gamma:=\left\{T(t): t \in R^{+}\right\}$be a strongly continuous L-Lipschitzian semigroup of pseudo-contractive mappings and $\left\{x_{n}\right\}$ be generated by (1.2). If

$$
\lim _{n \rightarrow \infty} \frac{\alpha_{n}}{t_{n}}=\lim _{n \rightarrow \infty} t_{n}=0,
$$

then $\left\{x_{n}\right\}$ converges strongly to a member of $F(\Gamma)$.

Proof: From the proof of Theorem 3.1, we know that $\left\{x_{n}\right\}$ is bounded and so there exists subsequence $\left\{x_{n_{j}}\right\} \subset\left\{x_{n}\right\}$ which converges weakly to some point $x^{*} \in K$. By Theorem 3.1, we have

$$
\lim _{n \rightarrow \infty}\left\|x_{n}-T(t) x_{n}\right\|=0
$$

It follows from [2, Theorem 3.18b] that $I-T(t)$ is demiclosed at zero for each $t \in R^{+}$, where $I$ is an identity mapping. This implies that $x^{*} \in F(\Gamma)$.

In addition, from (1.2), we have

$$
\begin{aligned}
\left\|x_{n}-x^{*}\right\|^{2} & =\alpha_{n}\left\langle u-x^{*}, x_{n}-x^{*}\right\rangle+\left(1-\alpha_{n}\right)\left\langle T\left(t_{n}\right) x_{n}-x^{*}, x_{n}-x^{*}\right\rangle \\
& \leqslant \alpha_{n}\left\langle u-x^{*}, x_{n}-x^{*}\right\rangle+\left(1-\alpha_{n}\right)\left\|x_{n}-x^{*}\right\|^{2}
\end{aligned}
$$

and so

$$
\left\|x_{n}-x^{*}\right\|^{2} \leqslant\left\langle u-x^{*}, x_{n}-x^{*}\right\rangle .
$$

This implies that $\left\{x_{n_{j}}\right\}$ converges strongly to $x^{*} \in F(\Gamma)$. Similar to the proof of Theorem 3.2 , it is easy to show that $\left\{x_{n}\right\}$ converges strongly to $x^{*} \in F(\Gamma)$. This completes the proof.

REMARK 3.3. Theorem 3.4 extends the results of Suzuki [9] and Xu [12] from nonexpansive semigroup to pseudo-contractive semigroup in real Hilbert spaces.

Now we turn to discuss the convergence of implicit iteration process (1.4) for approximating the common fixed point of the pseudo-contractive semigroup $\Gamma:=\{T(t): t \geqslant 0\}$.

THEOREM 3.5. Let $K$ be a nonempty closed convex subset of a real Banach space $E$ and $\Gamma:=\left\{T(t): t \in R^{+}\right\}$be a strongly continuous $L$-Lipschitzian semigroup of 
pseudo-contractive mappings. Then the sequence $\left\{x_{n}\right\}$ generated by (1.4) is well defined. Moreover, if

$$
\lim _{n \rightarrow \infty} \frac{\alpha_{n}}{t_{n}}=\lim _{n \rightarrow \infty} t_{n}=0
$$

then $\lim _{n \rightarrow \infty}\left\|x_{n}-T(t) x_{n}\right\|=0$ for any $t \in R^{+}$and $\lim _{n \rightarrow \infty}\left\|x_{n}-p\right\|$ exists for any $p \in F(\Gamma)$. Furthermore, if $E$ is a uniformly convex Banach space with the uniformly Gâteaux differential norm and condition (2) of Theorem 3.2 holds, then $\left\{x_{n}\right\}$ converges strongly to a member of $F(\Gamma)$.

Proof: Let

$$
T_{n} x:=\alpha_{n} x_{n-1}+\left(1-\alpha_{n}\right) T\left(t_{n}\right) x, \quad \forall n \geqslant 1 .
$$

It is obvious that $T_{n}$ is strongly pseudo-contractive and strongly continuous. From Lemma 2.1 , it is easy to know that $\left\{x_{n}\right\}$ generated by (1.4) is well defined.

Taking $p \in F(\Gamma)$, it follows that

$$
\begin{aligned}
\left\|x_{n}-p\right\|^{2} & =\alpha_{n}\left\langle x_{n-1}-p, j\left(x_{n}-p\right)\right\rangle+\left(1-\alpha_{n}\right)\left\langle T\left(t_{n}\right) x_{n}-T\left(t_{n}\right) p, j\left(x_{n}-p\right)\right\rangle \\
& \leqslant \alpha_{n}\left\|x_{n-1}-p\right\|\left\|j\left(x_{n}-p\right)\right\|+\left(1-\alpha_{n}\right)\left\|x_{n}-p\right\|^{2} \\
& =\alpha_{n}\left\|x_{n-1}-p\right\|\left\|x_{n}-p\right\|+\left(1-\alpha_{n}\right)\left\|x_{n}-p\right\|^{2}
\end{aligned}
$$

and so $\left\|x_{n}-p\right\| \leqslant\left\|x_{n-1}-p\right\|$. This means $\lim _{n \rightarrow \infty}\left\|x_{n}-p\right\|$ exists for any $p \in F(\Gamma)$. Similar to the proof of Theorem 3.1, we have $\lim _{n \rightarrow \infty}\left\|x_{n}-T(t) x_{n}\right\|=0$ for any $t \in R^{+}$.

From (1.4) and (3.4), for any $x^{*} \in C \cap F(\Gamma)$, we have

$$
\operatorname{LIM}\left\langle x_{n}-x_{n-1}, j\left(x_{n}-x^{*}\right)\right\rangle \leqslant 0 .
$$

Since $\left\|x_{n}-p\right\| \leqslant\left\|x_{n-1}-p\right\|$, we know that $\left\{x_{n}\right\}$ is bounded. Similar to the proof of (3.5), we have

$$
\operatorname{LIM}\left\langle x_{n-1}-x^{*}, j\left(x_{n}-x^{*}\right)\right\rangle \leqslant 0 .
$$

Adding inequalities (3.7) and (3.8), we get

$$
\operatorname{LIM}\left\langle x_{n}-x^{*}, j\left(x_{n}-x^{*}\right)\right\rangle=\operatorname{LIM}\left\|x_{n}-x^{*}\right\|^{2} \leqslant 0 .
$$

This implies that there exists subsequence $\left\{x_{n_{j}}\right\} \subset\left\{x_{n}\right\}$ which converges strongly to $x^{*}$. Since $\lim _{n \rightarrow \infty}\left\|x_{n}-x^{*}\right\|$ exists, it follows that $\left\{x_{n}\right\}$ converges strongly to $x^{*} \in F(\Gamma)$. This completes the proof.

If $\Gamma:=\left\{T(t): t \in R^{+}\right\}$is a nonexpansive semigroup, then $\Gamma:=\{T(t)$ : $\left.t \in R^{+}\right\}$is a strongly continuous $L$-Lipschitzian semigroup of pseudo-contractive mappings. Therefore, Theorem 3.5 gives the following result. 
COROLlary 3.2. Let $E$ be a uniformly convex Banach space with the uniformly Gâteaux differential norm and $K$ be a nonempty closed convex subset of $E$. Let $\Gamma:=\left\{T(t): t \in R^{+}\right\}$be a nonexpansive semigroup and $\left\{x_{n}\right\}$ be generated by (1.4). If

$$
\lim _{n \rightarrow \infty} \frac{\alpha_{n}}{t_{n}}=\lim _{n \rightarrow \infty} t_{n}=0,
$$

then $\left\{x_{n}\right\}$ converges strongly to a member of $F(\Gamma)$.

THEOREM 3.6. Let $E$ be a uniformly smooth Banach space and $K$ be a nonempty closed convex subset of $E$. Let $\Gamma:=\left\{T(t): t \in R^{+}\right\}$be a nonexpansive semigroup and $\left\{x_{n}\right\}$ be generated by (1.4). If

$$
\lim _{n \rightarrow \infty} \frac{\alpha_{n}}{t_{n}}=\lim _{n \rightarrow \infty} t_{n}=0,
$$

then $\left\{x_{n}\right\}$ converges strongly to a member of $F(\Gamma)$.

Proof: For the nonexpansive semigroup $\Gamma$, condition (2) of Theorem 3.2 is trivial and so formula (3.2) holds. Since uniformly smooth Banach space $E$ has the fixed point property for nonexpansive mapping $T(t)$ (see, for example, [11]), $T(t)$ has a fixed point $x^{*} \in C \cap F(\Gamma)$. The rest proof is similar to the proof of Theorem 3.5 and so we omit it. This completes the proof.

THEOREM 3.7. Let $E$ be a real Hilbert space and $K$ be a nonempty closed convex subset of $E$. Let $\Gamma:=\left\{T(t): t \in R^{+}\right\}$be a strongly continuous L-Lipschitzian semigroup of pseudo-contractive mappings and $\left\{x_{n}\right\}$ be generated by (1.4). If

$$
\lim _{n \rightarrow \infty} \frac{\alpha_{n}}{t_{n}}=\lim _{n \rightarrow \infty} t_{n}=0
$$

then $\left\{x_{n}\right\}$ converges weakly to a member of $F(\Gamma)$.

Proof: From Theorem 3.5 and the fact that $I-T(t)$ is demiclosed at zero for each $t \in R^{+}$, we know that $\left\{x_{n}\right\}$ is bounded and so there exists subsequence $\left\{x_{n_{j}}\right\} \subset\left\{x_{n}\right\}$ which converges weakly to some fixed point $x^{*} \in F(\Gamma)$. Suppose there exists another subsequence $\left\{x_{n_{k}}\right\} \subset\left\{x_{n}\right\}$ which converges weakly to $y^{*} \in F(\Gamma)$ with $y^{*} \neq x^{*}$. Since $\lim _{n \rightarrow \infty}\left\|x_{n}-y^{*}\right\|$ exists and Hilbert space $E$ satisfies Opial's condition, it follows from the standard argument that $y^{*}=x^{*}$. Thus, $\left\{x_{n}\right\}$ converges weakly to a member of $F(\Gamma)$. This completes the proof.

REMARK 3.4. Theorems 3.5 and 3.7 extend the corresponding results of Osilike [6] from the finite family of pseudo-contractive mappings to the pseudo-contractive semigroup.

\section{REFERENCES}

[1] F.E. Browder, 'Fixed point theorems for noncompact mappings in Hilbert space', Proc. Nat. Acad. Sci. U.S.A. 53 (1965), 1272-1276. 
[2] F.E. Browder, 'Nonlinear mappings of nonexpansive and accretive type in Banach spaces', Bull. Amer. Math. Soc. 73 (1967), 875-882.

[3] K. Deimling, 'Zeros of accretive operators', Manuscripta Math. 13 (1974), 283-288.

[4] T. Kato, 'Nonlinear semigroups and evolution equations', J. Math. Soc. Japan 19 (1967), 508-520.

[5] Z. Opial, 'Weak convergence of successive approximations for nonexpansive mappings', Bull. Amer. Math. Soc. 73 (1967), 591-597.

[6] M.O. Osilike, 'Implicit iteration process for common fixed points of a finite family of pseudocontractive maps', Panamer. Math. J. 14 (2004), 89-98.

[7] W.V. Petryshyn, 'A characterization of strictly convexity of Banach spaces and other uses of duality mappings', J. Func. Anal. 6 (1970), 282-291.

[8] S. Reich, 'Strong convergence theorems for resolvents of accretive operators in Banach spaces', J. Math. Anal. Appl. 75 (1980), 287-292.

[9] T. Suzuki, 'On strong convergence to common fixed points of nonexpansive semigroups in Hilbert spaces', Proc. Amer. Math. Soc. 131 (2002), 2133-2136.

[10] W. Takahashi, Nonlinear functional analysis (Yokohama Publisher, Yokohama, 2000).

[11] H.K. Xu, 'Viscosity approximation methods for nonexpansive mappings', J. Math. Anal. Appl. 298 (2004), 279-291.

[12] H.K. Xu, 'A strong convergence theorem for contraction semigroup in Banach spaces', Bull. Austral. Math. Soc. 72 (2005), 371-379.

[13] H.K. Xu and R.G. Ori, 'An implicit iteration process for nonexpansive mappings', Numer. Funct. Anal. Optim. 22 (2001), 763-773.

Department of Mathematics

Sichuan University

Chengdu

Sichuan, 610064

People's Republic of China

e-mail: xuesongli78@hotmail.com

nanjinghuang@hotmail.com 